\section{Next generation technology for utilization of alumina rich iron ore tailings in India}

\author{
Sudipta Mukopadhyay, Muthaimanoj Periyasamy \\ Indian Institute of Engineering Science and Technology, \\ Shibpur, West Bengal, India
}

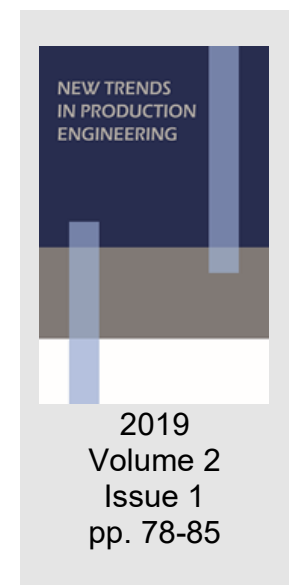

Date of submission to the Editor: 05/2019

Date of acceptance by the Editor: 07/2019

\title{
INTRODUCTION
}

Iron ore tailings (IOTs) is micro fines (less than $0.21 \mathrm{~mm}$ ) which has generated as a waste during the processing of high grade iron ores for iron and steel making (Pradip 2006). With ca. 5\% of the earth crust consisting of iron, iron ranks fourth most abundant element in the earth crust (Müller, Wang et al. 2006, Yellishetty, Ranjith et al. 2010). Steel is the widely used material, comprising $90 \%$ of the metal tonnage produced worldwide (Müller, Wang et al. 2006, Yellishetty, Ranjith et al. 2010). Because of the growing global demand for steel products, especially in India there will be a huge iron ore crisis in the future (Yellishetty, Ranjith et al. 2010).

At present, there is a massive steel consumption rate due to rapid infrastructure development and industrialization in India. Based on the forecast, there will be a huge demand for the finished iron and steel products in near future (Association 2014). India is world's third largest producer of crude steel, producing 101.4 million tonnes in 2017 followed by an annual steel consumption of ca.87.2 million tonnes in Financial year of 2017 (Association 2014). In order to meet these demands, there is continuous excavation of present iron ore resources for iron and steel making. Indian iron ore are rich in iron values but also contains high alumina (around 7\%) (Pradip 2006).

In order to remove the gangue minerals from the iron ore, the excavated alumina rich iron ores has subjected to washing. The current washing practice results in three products, the coarser lump ores $(-200-10 \mathrm{~mm})$, classifier fines $(-10 \mathrm{~mm})$ and slimes $(-0.1 \mathrm{~mm})$. Due to high iron values, the coarser lump ores were directly used for $\mathrm{BF}$ (blast furnace) operation by converting them into sinters and pellet products (Pradip 2006). The CF (classifier fines) generated has high alumina and silica content, which can be used further with or without suitable mineral beneficiation route. During the processing of huge CF, a large amount of micro fines with high alumina and silica value has generated. Due to high 
alumina value and complex mineral texture, these iron ore tailings were difficult to process and currently discarded as a waste material in mine sites.

Accumulation of 8-10 million tons of iron ore tailing (a mine waste) per year ( 48$60 \% \mathrm{Fe}$ ) in Indian iron ore mines generated during rapid excavation and processing of high grade iron ore deposits puts a big question in sustainable mine practice followed till date (Ghose and Sen 2001). The unutilized mine waste may create environmentally damaging issues, placing more pressure on the mine operations (Rudramuniyappa 1997). Recent failure (25-January-2019) of Vale's Brumadinho iron ore tailings dam in Brazil creates a major overwhelming impact in the world iron ore trades and creates a big environmental issue (Fiscor 2019, Porsani, Jesus et al. 2019). The key reason behind the tailing dam failure is continuous accumulation of waste minerals and poor maintenance of upstream dams as stated by International Commission on Large Dams (ICOLD) and the United Nations Environment Programme (UNEP) (Gray 1990). In order to avoid the above-mentioned problems, several research and industrial works has carried out for utilizing these mine waste for future needs. Many works has carried out on effective recuperation of iron ore values from mine tailings but the work became unfinished due to less iron recovery and less (economic/industrial) benefit.

\section{PHYSIO-CHEMICAL PROPERTIES OF IOTS}

IOTs consists of a mixture of compounds originally present in the parent mineral and those introduced during the beneficiation process. The main constituents of IOTs include $\mathrm{Fe}_{2} \mathrm{O}_{3}, \mathrm{Al}_{2} \mathrm{O}_{3}, \mathrm{SiO}_{2}, \mathrm{MgO}$ and number of minor constituents like $\mathrm{K}$, $\mathrm{P}$ etc ( $\mathrm{Li}$, Sun et al. 2010). Indian iron ores of Precambrian origin generally contains hematite as a major constituent. Mineralogical constituents identified in a typical iron ore tailings has identified by X-ray diffraction analysis ( $\mathrm{Li}$, Sun et al. 2010). The sintered products from the high grade iron ores contains alumina value less than $1 \%$, whereas the alumina value in the Indian IOTs were higher than $3-5 \%$ (Table 1).

Table 1 Results of few studies on Processing of Indian iron ore tailings

\begin{tabular}{|c|c|c|c|c|}
\hline Plant details & $\begin{array}{c}\text { Beneficiation routes } \\
\text { used }\end{array}$ & $\begin{array}{l}\text { Ore grade } \\
\text { (initial) }\end{array}$ & $\begin{array}{l}\text { Ore grade } \\
\text { (final) }\end{array}$ & $\begin{array}{l}\text { Weight } \\
\text { recovery }\end{array}$ \\
\hline $\begin{array}{l}\text { Noamundi iron ore } \\
\text { washing plant (TISCO) } \\
\text { (Das, Prakash et al. 1992) }\end{array}$ & Hydrocyclone & $\begin{array}{c}\mathrm{Fe} 57 \% \\
\mathrm{Al}_{2} \mathrm{O}_{3} 8.3 \% \\
\mathrm{SiO}_{2} 4.0\end{array}$ & $\begin{array}{c}\mathrm{Fe} 64 \% \\
\mathrm{Al}_{2} \mathrm{O}_{3} 3.5 \\
\mathrm{SiO}_{2} 1.4 \\
\end{array}$ & $49 \%$ \\
\hline $\begin{array}{l}\text { Chitradurga iron ore } \\
\text { washing plant (Roy, Das et } \\
\text { al. 2007) }\end{array}$ & $\begin{array}{l}\text { Hydrocyclone } \\
\text { Wilfey table } \\
\text { WHIMS } \\
\text { Flotation }\end{array}$ & $\begin{array}{l}\mathrm{Fe} 49.86 \% \\
\mathrm{Al}_{2} \mathrm{O}_{3} 8.3 \% \\
\mathrm{SiO}_{2} 4.0 \%\end{array}$ & $\begin{array}{c}\mathrm{Fe} 63.36 \\
\mathrm{Al}_{2} \mathrm{O}_{3} 1.75 \% \\
\mathrm{SiO}_{2} 1.44 \%\end{array}$ & $\begin{array}{c}25 \% \\
40 \% \\
\text { (continuous } \\
\text { operation) } \\
\end{array}$ \\
\hline $\begin{array}{l}\text { Joda east iron ore mines } \\
\text { (Thella, Mukherjee et al. } \\
\text { 2012) }\end{array}$ & $\begin{array}{l}\text { Hydrocyclone } \\
\text { Flotation }\end{array}$ & $\begin{array}{c}\mathrm{Fe} 54.93 \% \\
\mathrm{Al}_{2} \mathrm{O}_{3} 6.62 \% \\
\mathrm{SiO}_{2} 7.45 \% \\
\end{array}$ & $\begin{array}{c}\mathrm{Fe} 64.46 \% \\
\mathrm{Al}_{2} \mathrm{O}_{3} 2.66 \% \\
\mathrm{SiO}_{2} 2.05 \% \\
\end{array}$ & $69.03 \%$ \\
\hline $\begin{array}{l}\text { Jilling langaot iron ore } \\
\text { mine } \\
\mathrm{m} / \mathrm{s} \text { Essel mining and } \\
\text { industries (Roy and Das } \\
2008 \text { ) }\end{array}$ & $\begin{array}{l}\text { Hydrocyclone } \\
\text { WHIMS } \\
\text { Wilfey tabiling } \\
\text { Flotation }\end{array}$ & $\begin{array}{c}\mathrm{Fe} 37.86 \% \\
\mathrm{Al}_{2} \mathrm{O}_{3} 14.4 \% \\
\mathrm{SiO}_{2} 19.08 \%\end{array}$ & $\begin{array}{l}\mathrm{Fe} 66.97 \% \\
\mathrm{Al}_{2} \mathrm{O}_{3} 1.7 \% \\
\mathrm{SiO}_{2} 1.52 \%\end{array}$ & $15 \%$ * \\
\hline $\begin{array}{l}\text { Donimali iron ore mine- } \\
\text { NMDC Itd (Rao, } \\
\text { Markandeya et al. 2016) }\end{array}$ & $\begin{array}{l}\text { Hydrocyclone } \\
\text { WHIMS }\end{array}$ & $\begin{array}{c}\mathrm{Fe} 49.40 \% \\
\mathrm{Al}_{2} \mathrm{O}_{3} 13.51 \% \\
\mathrm{SiO}_{2} 8.44 \% \\
\end{array}$ & $\begin{array}{c}\mathrm{Fe} 65.93 \% \\
\mathrm{Al}_{2} \mathrm{O}_{3} 1.45 \% \\
\mathrm{SiO}_{2} 1.94 \% \\
\end{array}$ & $45.18 \%$ \\
\hline
\end{tabular}


Increase in the alumina content on the sinter products will leads to a significant adverse effect on the sinter strength and reduction degradation characteristics (RDI), which leads to decline in gas permeability in the upper part of the blast furnace (BF) (Pradip 2006). Higher the alumina in the sinter products leads to produce slag of high alumina content; high viscous alumina rich BF slag requires high flux material (10\% MgO) to reduce its viscosity (Pradip 2006). Addition of flux material in the BF slag increases the slag volume, which results in high coke consumption and decrease in blast furnace productivity. Based on the previous studies it has documented that decrease in the alumina value in the sinter products will improve the RDI value and lowers the coke consumption, which in turn results in high blast furnace productivity. Considering the fact that the rapid depletion of high-grade iron ore resources opens up the technical possibilities of utilizing these low-grade tailings for future demands.

\section{BENEFICIATION PROCESS AND WORK DONE SO FAR}

Several attempts has made to recover the iron values from the tailings through conventional mineral processing routes such as hydrocyclone, magnetic separation (incudes wet high intensity magnetic separation (WHIMS)), froth flotation and selective flocculation process (Das, Prakash et al. 1992, Pradip 2006, Roy, Das et al. 2007, Roy and Das 2008, Li, Sun et al. 2010, Thella, Mukherjee et al. 2012, Rao, Markandeya et al. 2016). Table 1 shows the proposed experimental conditions and results obtained on processing of iron ore tailings in India iron ore mines. Based on the experimental proofs, it is obvious that by the existing mineral dressing technologies the recovery of iron values had limited to $50 \%$.

\section{Dissolution behaviour of iron oxides}

Due to the massive limitation in the solid recovery along with a major loss of iron values as residual waste during the physical and physicochemical process leads to shed light on the chemical approach. Chemical approach (hydrometallurgy) involves dissolution of metal or metals from an ore or concentrate into a solution, this process is termed as leaching (Havlík, 2014). Several research works has carried out to evaluate the dissolution of iron with help of inorganic and organic acids (Cornell and Schwertmann, 2003). Iron oxide dissolution can be proceeded by different pathways, viz. protonation, complexation and reduction, photochemical and biological (Havlík 2014).

Sidhu, P. S., et al. studied the the dissolution rate of the iron oxides in presence of hydrochloric/per chloric acids: lepidocrocite $>$ magnetite $>$ akaganeite $>$ maghemite $>$ hematite $>$ goethite, the study proves that the chemical composition and crystal structure plays a major role in leaching process (Sidhu, Gilkes et al. 1981). Among several mineral acids used for the dissolution of iron oxides, hydrochloric acid has found to be more effective due to its high complexing ability with the iron species (Parida and Das 1996). Parida, K. M., and N. N. Das. Studied the dissolution behaviour of hematite ore in hydrochloric medium with or without the presence of reducing agents, in this work the effect 
acid concentration, temperature, liquid/solid ratio, particle size and reductant concentration with respect to the amount of dissolution of iron minerals has widely studied (Parida and Das 1996). It is evident that the amount of dissolution of iron minerals increases with steady increase in the acid concentration and temperature (ref). Sidhu, P. S., et al. proves the influence of particle size and surface area on the dissolution, that there is a linear relationship between the amount of dissolution to the initial surface area (Sidhu, Gilkes et al. 1981). Several studies were carried out to replace the high temperature chlorination technique by using different inorganic and organic acids for the dissolution of iron species (Cornell and Schwertmann 2003). Ambikadevi, V.R., and M. Lalithambika have tested several organic acids such as acetic, formic, citric, ascorbic and oxalic acid, from which they have finalised that the oxalic acid is the prominent that can able to dissolute iron oxide from the ceramic minerals (Ambikadevi and Lalithambika 2000). Processing of the residual iron ore tailings have become a urgent need, so sustained and systematic interdisciplinary effort has to be made on designing an environmentally benign process for recovery of iron minerals through hydrometallurgical route.

\section{Producing value added products from mine waste Iron Containing nanomaterials from mine residue}

Low valued residual waste material obtained from the iron ore mines acting as either iron precursor for producing nanomaterials or can utilized as a catalyst directly. In following sections, a detailed study on the synthesis, characterization and application of the nanomaterials synthesised from mine waste has discussed briefly. Darezereshki, E. et al. presents a detailed information on the successful synthesis routes and conditions followed in synthesis of iron containing nanomaterials (ICN's) from mine waste (Darezereshki, Khodadadi Darban et al. 2018).

\section{General synthetic methods for preparing ICN's using mine waste}

As like other nanoscale materials, ICNs obtained from natural ore has synthesised via both top down approach and bottom up approach. Due to technical and economic limitation, only limited works has carried out on producing ICNs through top down approach. Top down approach involves breaking down the magnetically separated gangue free bulk iron material into nanometre scale fragments through mechanical means (Yan, Lien et al. 2013, Priyadarshana, Kottegoda et al. 2015). Due to several limitations in the top down method, the bottom up approach was much favoured and adored for its easy control and cost effectiveness. Bottom-up approaches involve bringing together iron atoms to form iron oxide clusters at the nanometre scale, which has archived by aqueous co-precipitation of aqueous $\mathrm{Fe}_{2}+/ \mathrm{Fe}_{3}+$ acid soluble hydrolysate by addition of a base, micro emulsion technique, ultrasound approach and hydrothermal synthesis (Petcharoen and Sirivat 2012). Darezereshki et al. archived the widely accepted routes and conditions followed for the synthesis of magnetite nanoparticles from the mine waste (Darezereshki, 
khodadadi Darban et al. 2018). Methods for characterizing the pertinent properties of magnetite nanoparticles synthesised from mine waste has summarized in Table 2.

Table 2 Methods for characterizing some pertinent properties of ICN's synthesised from mine waste

\begin{tabular}{|c|c|c|}
\hline \multicolumn{3}{|c|}{ General characterization } \\
\hline Property & Assessment method & Reported characteristics \\
\hline Morphology & SEM,FESEM,TEM & $\begin{array}{l}\text { ICN's are almost spherical or cubical, } \\
\text { generally particles associated to form } \\
\text { agglomerates in absence of surface } \\
\text { stabilizers. (Kumar, Sakthivel et al. 2015) }\end{array}$ \\
\hline $\begin{array}{l}\text { Size and Size } \\
\text { distribution }\end{array}$ & $\begin{array}{l}\text { Size of dry particles: } \\
\text { electron microscopic } \\
\text { observation }\end{array}$ & $\begin{array}{l}\text { Primary particles } 10-100 \mathrm{~nm} \text {. The particles } \\
\text { size mostly depends on the synthesis route } \\
\text { and stabilizers used. (Giri, Das et al. 2011) }\end{array}$ \\
\hline $\begin{array}{l}\text { Specific surface } \\
\text { area }\end{array}$ & $\begin{array}{l}\text { Brunauer-Emmett-Teller } \\
\text { isotherm gas adsorption }\end{array}$ & $\begin{array}{l}\text { 10-64.04 } \mathrm{m}^{2} / \mathrm{g} \text { (Darezereshki, Khodadadi } \\
\text { Darban et al. 2018) }\end{array}$ \\
\hline $\begin{array}{l}\text { Crystallographic } \\
\text { characterization }\end{array}$ & $\begin{array}{l}\text { Electron diffraction, X-ray } \\
\text { diffraction (for grain sizes } \\
\text { larger than a few } \mathrm{nm} \text { ) }\end{array}$ & $\begin{array}{l}\text { Identified degree of crystallinity varies with } \\
\text { synthesis routes. } \\
\text { Major ICN's synthesised were of Magnetite } \\
\left(\mathrm{Fe}_{3} \mathrm{O}_{4}\right) \text { crystal phase (Giri, Das et al. 2011, } \\
\text { Kumar, Sakthivel et al. 2015, Darezereshki, } \\
\text { Khodadadi Darban et al. } 2018 \text { ) }\end{array}$ \\
\hline
\end{tabular}

\section{ICNs for environmental applications}

Rapid industrial revolution alongside creates severe water consumption and pollution of water bodies through industrial effluents released during different industrial activities, which results in clean water crisis. Industrial effluents such as dyes, antibiotics, pesticides, heavy metals, inorganic compounds and other complex compounds mix up with the water bodies and creates sever environmental issue. However, conventional biological treatment has become a huge failure, as the intermediates generated during the treatment were highly toxic and carcinogenic in nature. In order to combat the problem of industrial water pollution, nanotechnology has suggested as a cost effective and efficient alternative than any other existing methods. Among several conventional treatment methods available, the recent advancements in the nanotechnology on the as adsorption, filtration and ion exchange resins for wastewater treatment holds a higher hand in present days. These methods lack its advantages in that way these methods simply transfer the pollutants to another phase rather than destroying them.

To overcome the inconvenience of the conventional water treatment method an emerging advanced oxidation process (AOPs) were used an alternative for the conventional water treatment. AOPs involves generation of strong oxidizing species such as $. \mathrm{OH}, \mathrm{O}_{2-}$. to break down the macromolecules into smaller and less harmful substances (Rauf, Meetani et al. 2011). Some of the wellestablished AOP process were UV photolytic technique (ref), Fenton process (ref), photo-Fenton process, ozonation process (ref), sonolysis (ref) and photocatalysis process (ref). However the conventional catalysts used in the above said process are more or less unsatisfactory due to the low efficiency or being expensive. In order to overcome these issue IOTs and acid mine drainage 
(AMD) has used as a starting material for the inexpensive catalyst (Muthukannan, Praveen et al. 2015).

\section{CONCLUSION}

Due to rapid depletion of iron ore resources and increased solid waste generation during the mining process had caused serious environmental and sustainability issues. This has made an increasing interest in the use of the accumulated iron ore tailings to attain a zero waste production and sustainable mine practice. In current mineral processing practise, the yield percentage of iron values has limited to ca. $50 \%$ and leaves in generation of large amount of residual wastes. It is extremely important to utilize these residual IOTs for the synthesis of value added products. Moreover, the procedure selected for obtaining high-grade iron values from the IOT's was leaching process. Selection of suitable inorganic and organic acids for accomplishing the iron value separation has identified as a key research challenge, a critical review of the work done so far on the processing of low-grade iron ores through hydrometallurgy route and development of Value added products from the hydrolysate had discussed in detail. The use of these synthesised ICN's for environmental issues has kept as a research challenge faced by current developing nations.

\section{REFERENCES}

Ambikadevi, V. and M. Lalithambika (2000). "Effect of organic acids on ferric iron removal from iron-stained kaolinite." Applied Clay Science 16(3-4): 133-145.

Association, W.S. (2014). "World steel in figures 2014." World Steel Association: Brussels, Belgium.

Cornell, R.M. and U. Schwertmann (2003). The iron oxides: structure, properties, reactions, occurrences and uses, John Wiley \& Sons.

Darezereshki, E., A. Khodadadi Darban and M. Abdollahy (2018). "Synthesis of magnetite nanoparticles from iron ore tailings using a novel reductionprecipitation method." Journal of Alloys and Compounds 749: 336-343.

Das, B., S. Prakash, B. Mohapatra, S. Bhaumik and K. Narasimhan (1992). "Beneficiation of iron ore slimes using hydrocyclone." Mining, Metallurgy \& Exploration 9(2): 101-103.

Fiscor, S. (2019). "Dam Failure Pushes Iron Ore Prices Higher." Precious Metals.

Ghose, M. and P. Sen (2001). "Assessment of effective design of tailing pond for safe disposal of iron ore tailings."

Giri, S., N. Das and G. Pradhan (2011). "Synthesis and characterization of magnetite nanoparticles using waste iron ore tailings for adsorptive removal of dyes from aqueous solution." Colloids and Surfaces A: Physicochemical and Engineering Aspects 389(1-3): 43-49.

Gray, M.A. (1990). "The United Nations Environment Programme: An Assessment." Envtl. L. 20: 291.

Havlík, T. (2014). Hydrometallurgy: Principles and applications, Elsevier.

Kumar, R., R. Sakthivel, R. Behura, B. Mishra and D. Das (2015). "Synthesis of magnetite nanoparticles from mineral waste." Journal of Alloys and Compounds 645: 398-404.

Li, C., H. Sun, J. Bai and L. Li (2010). "Innovative methodology for comprehensive utilization of iron ore tailings: Part 1 . The recovery of iron from iron ore tailings 
using magnetic separation after magnetizing roasting." Journal of Hazardous Materials 174(1-3): 71-77.

Müller, D.B., T. Wang, B. Duval and T.E. Graedel (2006). "Exploring the engine of anthropogenic iron cycles." Proceedings of the National Academy of Sciences 103(44): 16111-16116.

Muthukannan, V., K. Praveen and B. Natesan (2015). "Fabrication and characterization of magnetite/reduced graphene oxide composite incurred from iron ore tailings for high performance application." Materials Chemistry and Physics 162: 400-407.

Parida, K. and N. Das (1996). "Reductive dissolution of hematite in hydrochloric acid medium by some inorganic and organic reductants: A comparative study."

Petcharoen, K. and A. Sirivat (2012). "Synthesis and characterization of magnetite nanoparticles via the chemical co-precipitation method." Materials Science and Engineering: B 177(5): 421-427.

Porsani, J.L., F.A.N. d. Jesus and M.C. Stangari (2019). "GPR Survey on an Iron Mining Area after the Collapse of the Tailings Dam I at the Córrego do Feijão Mine in Brumadinho-MG, Brazil." Remote Sensing 11(7): 860.

Pradip (2006). "Processing of alumina-rich Indian iron ore slimes." TRANSACTIONS OF THE INDIAN INSTITUTE OF METALS 59(5): 551-568.

Priyadarshana, G., N. Kottegoda, A. Senaratne, A. d. Alwis and V. Karunaratne (2015). "Synthesis of magnetite nanoparticles by top-down approach from a high purity ore." Journal of Nanomaterials 16(1): 317.

Rao, G., R. Markandeya and S. Sharma (2016). "Recovery of Iron Values from Iron Ore Slimes of Donimalai Tailing Dam." Transactions of the Indian Institute of Metals 69(1): 143-150.

Rauf, M., M. Meetani and S. Hisaindee (2011). "An overview on the photocatalytic degradation of azo dyes in the presence of $\mathrm{TiO} 2$ doped with selective transition metals." Desalination 276(1-3): 13-27.

Roy, S. and A. Das (2008). "Characterization and processing of low-grade iron ore slime from the Jilling area of India." Mineral Processing \& Extractive Metallurgy Review 29(3): 213-231.

Roy, S., A. Das and M. Mohanty (2007). "Feasibility of producing pellet grade concentrate by beneficiation of iron ore slime in India." Separation Science and Technology 42(14): 3271-3287.

Rudramuniyappa, M. (1997). "Iron ore fines and their impact on environment in SandurHospet region, Bellary district, Karnataka, India."

Sidhu, P., R. Gilkes, R. Cornell, A. Posner and J. Quirk (1981). "Dissolution of iron oxides and oxyhydroxides in hydrochloric and perchloric acids." Clays and Clay Minerals 29(4): 269-276.

Thella, J.S., A.K. Mukherjee and N.G. Srikakulapu (2012). "Processing of high alumina iron ore slimes using classification and flotation." Powder Technology 217: 418426.

Yan, W., H.-L. Lien, B.E. Koel and W.-x. Zhang (2013). "Iron nanoparticles for environmental clean-up: recent developments and future outlook." Environmental Science: Processes \& Impacts 15(1): 63-77.

Yellishetty, M., P. Ranjith and A. Tharumarajah (2010). "Iron ore and steel production trends and material flows in the world: Is this really sustainable?" Resources, conservation and recycling 54(12): 1084-1094. 
Abstract.

Accumulation of low-grade iron ore tailings (IOTs) generated during the processing of highgrade iron ore has become a great threat to environment. Although wide range of research works has carried out to recover the iron values from the IOTs, but the solid recovery value has limited to ca. $50 \%$ in Indian context. In order to attain a maximum iron recovery and to utilize these solid wastes for future needs, an attention has shed on the topics of hydrometallurgy and applied nanomaterial synthesis from IOTs. Iron containing nanoparticles (ICNs) have huge potential in environmental and energy related applications. A wide range of synthesis methods has developed to produce ICNs from the mine waste. It is evident from the recent research works that converting waste materials into value added products are gaining more attentions. Objective of this review is to analyse the green synthesis routes to prepare ICNs from mine waste, starting from the physio chemical identification of waste material followed by discussion on various methods of ICNs synthesis routes from mine waste. It includes selective leaching method. Finally, the use of ICNs for environmental application had discussed in brief

Keywords: Iron ore tailings (IOTs), Hydrometallurgy, Mineral processing, Iron containing nanoparticles (ICNs) 